\title{
Fibromyalgia with severe forms of progression in a multidisciplinary therapy setting with emphasis on hyperthermia therapy - a prospective controlled study
}

\author{
This article was published in the following Dove Press journal: \\ Clinical Interventions in Aging \\ 19 December 2014 \\ Number of times this article has been viewed
}

\author{
Tobias Romeyke \\ Hans Christoph Scheuer \\ Harald Stummer \\ Department of Public Health \\ and Health Technology Assessment, \\ Division for Organizational Behavior \\ Research and Workplace Health \\ Promotion, University for Health \\ Sciences, Medical Informatics \\ and Technology, Vienna, Austria
}

\begin{abstract}
Introduction: Fibromyalgia syndrome (FMS) is a multi-factorial disease involving physiological as well as psychological factors. The aim of the study was to investigate a multidisciplinary inpatient treatment with emphasis on hyperthermia therapy by patients with widespread pain. Materials and methods: The study involved 104 patients suffering from severely progressive FMS. A convenience sample and a prospective cohort design were used. The patients were treated in an acute hospital focusing on rheumatologic pain therapy and multidisciplinary complementary medicine. One patient group was treated with inclusion of hyperthermia therapy and the other group without. The therapy density (number of performed therapies per patient) was determined for every patient. Functional capacity measured by the Hannover functional status questionnaire (Funktionsfragebogen Hannover) and symptoms (von Zerssen complaint list) were analyzed for both groups on admission and on discharge.

Results: On admission, no significant difference could be established between control group (CG; multimodal without hyperthermia) and hyperthermia group (HG; multimodal with hyperthermia) (functional capacity, $P=0.936$ ). Functional capacity improved for the CG and the HG. On discharge, there was a significant difference between the two groups (functional capacity, $P=0.039$ ). There were no significant differences in fibromyalgia symptoms between CG (mean 41.8 ) and HG (mean 41.8) on their admission to hospital $(P=0.988)$. On discharge, there was a significant difference $(P=0.024)$ between the two groups ( $\mathrm{HG}$, mean 30.6; $\mathrm{CG}$, mean 36.6). The inpatient therapy of patients with severely progressive fibromyalgia is characterized by a high frequency of therapy input.
\end{abstract}

Conclusion: FMS, especially with severe progression and a high degree of chronification, demands a multidisciplinary approach. In addition to the use of complementary medical procedures, integration of hyperthermia in the treatment process is a useful option.

Keywords: fibromyalgia, hyperthermia, pain, multidisciplinary approach

\section{Background}

Fibromyalgia syndrome (FMS) is a multi-factorial disease involving physiological as well as psychological factors. It is characterized by widespread pain and muscle tenderness accompanied by other comorbid symptoms. ${ }^{1,2}$ Those affected report chronic pain, which persists for at least 3 months in several regions of the body. The affected areas include the neck or upper or middle back, the small of the back, ribcage or abdomen, and at least one site of pain in both arms and both legs.

Patients can also have difficulty in falling asleep and sleeping through the night; in the morning, they feel that they have had too little sleep, and in many cases,
Correspondence: Tobias Romeyke; Harald Stummer

Department of Public Health and Health

Technology Assessment, University for

Health Sciences, Medical Informatics and

Technology, Opernring 5/2, 1010 Vienna, Austria

Tel +43508648395I

Email tobias.romeyke@umit.at;

harald.stummer@umit.at 
feel mentally and physically exhausted. Numerous studies describe depression, anxiety, and panic disorders as comorbidities of FMS. ${ }^{3-5}$ Many sufferers report additional symptoms affecting the stomach, intestines, cardiovascular system, nervous system, or urinary passages. ${ }^{6,7}$

The pathophysiology of FMS is still unknown. It is assumed that the levels of biogenic amines such as 5-hydroxytryptamine (5-HT) and norepinephrine are reduced in persons with FMS. A dysfunction of the 5-HT system may lead to panic disorders and depression. ${ }^{8,9}$

Predictors of FMS are obesity, missing physical activity, high workload, ${ }^{10,11}$ increased physical discomfort, and permanent local pain for more than 6 years. ${ }^{12}$ Prevalence of FMS is estimated to be $5 \%-6 \%$ of women in the USA and Europe. ${ }^{13,14}$ Individuals with FMS report frequent health care use $^{15}$ concomitantly with lost productivity through higher absenteeism and unemployment. ${ }^{16}$ FMS places a significant economic burden on patients and health care systems. ${ }^{17,18}$

The complexity of the FMS, its chronic progression, and the heavy burden of suffering present health care providers with an extensive set of problems.

There is no universally acceptable treatment for this condition. ${ }^{19}$ FMS leads to substantial limitations in physical functioning and activities of daily living. A higher absenteeism, unemployment, and disability lead to significant costs.

Multidisciplinary approaches are recommended for the treatment of fibromyalgia. These should include both psychotherapeutic methods (patient education and/or cognitive behavioral therapy) and exercise and activating therapeutic procedures. $^{20,21}$

These complementary methods do not exert their effects individually, but exert synergistic effects. Decisions to use a multidisciplinary approach to therapy should be determined based on a structured health care assessment of the individual. ${ }^{22}$

Multidisciplinary approaches may include hydrotherapeutic and thermotherapeutic methods, hydrogalvanic baths (medical treatment [a type of electrotherapy] based on the simultaneous use of water and electric current), and acupuncture. Hydrotherapeutic methods are used by many individuals with FMS. ${ }^{23}$ These methods include balneotherapeutic methods of hydrotherapy (part of naturopathy and physiotherapy, that involves the use of water for pain relief and treatment), such as herbal baths, mud baths, steam baths, and hot water whirlpool baths to soothe muscles and stimulate circulation.

Hydrotherapy can contribute in particular to reduce pain safely ${ }^{24-26}$ and offers beneficial treatment with no hidden side effects. ${ }^{26}$ Hot baths ${ }^{27,28}$ are favored by many individuals with FMS and can be a therapy option to reduce high pain intensity. ${ }^{29}$ Acupuncture may be integrated into a multimodal therapy as an adjunctive treatment ${ }^{30}$ and may help to reduce FMS symptoms ${ }^{31,32}$ and to increase the quality of life. ${ }^{33}$

Conversations between health care providers during hospitalization should be client centered to improve and solidify the client-provider relationship. ${ }^{34}$ The therapist is able to understand what the individuals are feeling and provide care that is more specific to their needs and therefore provide better care. Individuals are more likely to engage in treatment decisions, feel supported to make behavioral changes, and so feel empowered to self-manage.

Psychotherapy should include established methods of coping with pain and deflecting attention, ${ }^{35}$ other problemsolving strategies, ${ }^{36}$ and cognitive behavioral therapy. ${ }^{37}$

Cognitive behavioral therapy is effective at helping you learn to manage your illness more effectively and it is based on the gate-control theory of pain and operant behavioral conditioning. ${ }^{38}$

Physical therapies are found to be especially effective in the treatment of FMS ${ }^{39}$ and also reflexology (physical act of applying pressure to the feet, hands, or ears with specific thumb, finger, and hand techniques). ${ }^{40}$ Therefore, these therapies are integral components of the physiotherapy used in performing the study.

\section{Hyperthermia}

Different methods of hyperthermia exist. ${ }^{41}$ The mechanism of action of heat therapy in a wide range of different diseases is also the subject of numerous studies ${ }^{42-45}$ but the mechanisms are currently not completely understood and are in need of further scientific investigation (Figure 1). Infrared (IR)-A radiation may cause an immediate cellular effect, increasing nuclear DNA and RNA synthesis and ferritin levels. ${ }^{46,47}$

Hyperthermia is usually incorporated with other complementary therapies. ${ }^{48}$ Several studies also have demonstrated

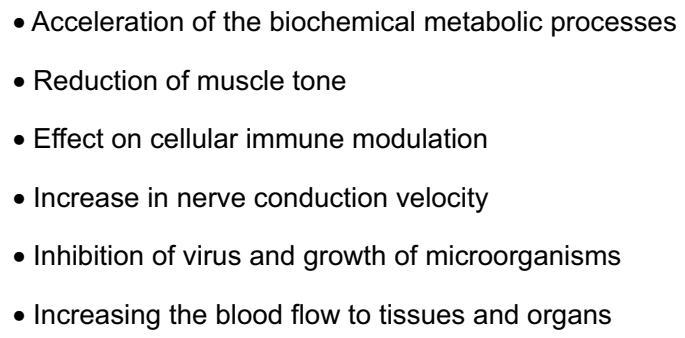

Figure I Assumed physiological effects of systemic whole-body hyperthermia. 
that IR-A radiation accelerates healing of both chronic and postoperative wounds and reduces postoperative pain medication use. ${ }^{49,50}$ The use of hyperthermia has recently been studied, but is in its early stages. ${ }^{51}$ Pain in individuals with FMS was reduced for several months after discharge from the hospital. ${ }^{52,53}$

\section{Methods Design}

The study design was a convenience sample and a prospective cohort study. The authors chose an understudied area and reported a cohort study to highlight the additive effects of hyperthermia therapy as part of an in-hospital, multimodality program for the symptom management of FMS. The data in the study were collected according to the hypothesis formation, specifically for testing the hypothesis. Before starting the analysis, groups of patient were formed who were as similar as possible regarding relevant factors; the classification of the individuals was made according to the International Classification of Diseases.

All individuals approached by the investigator agreed to participate with a declaration of consent. Clinical patient number and all social data were deleted after the survey. Study participants always retained the right to withdraw at any time, for any reason. The study complies with the targets of the local ethical review committee and the targets of the privacy policy. The inclusion criterion for hospitalized individuals to participate in the study was a primary rheumatologic diagnosis of FMS by a specialist.

Exclusion criteria for study were severe epilepsy, chronic infections, acute infections, and claustrophobia.

The participants fulfilled the criteria of the American College of Rheumatology for the FMS diagnosis and showed severe disease progression as demonstrated by the disease activity, symptoms, and functional capacity. All patients had comorbid disease, over 700 diagnoses in total, which will not be presented due to their complexity and scope. It was clearly evident that all the participants availed themselves of a wide variety of outpatient treatments (specialists, therapists, before hospitalization) on account of their FMS. For the measurement of chronic pain, the Mainz staging (Gerbershagen) was used. ${ }^{54,55}$ It was possible to blind outcome assessment by having this done by an independent person unaware of who received what. The investigators began enrolling subjects and collecting baseline exposure information; none of the subjects have developed any of the outcomes of interest.

During the entirety of their stay, all participants received interdisciplinary treatment from anesthesia specialist and internal medicine, rheumatology, and general medicine specialists. An integrative therapeutic approach in an acute setting is characterized by a high therapy density. ${ }^{56,57}$ If the application of hyperthermia is contraindicated, this is compensated by the use of other therapeutic procedures in order to ensure close-meshed, high-frequency therapy.

Nursing supervision was maintained. Process coordinators were in the middle of the workflow, deciding what information to share and when. The process coordinator was informed to collect all relevant parameters (disease activity, physical symptoms, functional capacity).

Complementary and alternative therapies were performed by a naturopathy specialist with the additional qualification, Naturheilverfahren (naturopathic methods), and with at least 3 years of experience in the field of "classical naturopathy". In addition to specialist doctors, the team included specially trained nursing staff with at least 6 months of naturopathy experience.

The treatments applied were evidence based and best practice methods from hydro-/thermotherapy, physical therapy, phytotherapy, psychotherapy, lifestyle regulative therapy, and movement therapy. In addition, neural therapy, acupuncture, infiltrations, homeopathy, and dietary consultations were performed according to indication (Table 1). ${ }^{58-70}$ There was a standardized time of exposure to each therapy written into the protocol.

Table I Excerpt of evidence-based treatment regime in a multimodal setting

Hydrotherapeutic methods ${ }^{65,66}$ : application of water through various methods (Kneipp treatments), eg, baths with added substances, mud baths, steam baths, water with whirlpool, bandages, or compresses

Thermotherapeutic methods ${ }^{70}$ : eg, infrared radiation only for hyperthermia group, heating pad, hot water bath

Psychotherapy ${ }^{62,63}$ : eg, CBT, mind-body therapy

Practical therapies ${ }^{67}:$ eg, movement therapy, occupational therapy

Pain therapy ${ }^{68,69}:$ eg, infiltration, cupping, cupping massage, acupuncture

Physiotherapy/physical therapy ${ }^{67}$ : eg, massage, transcutaneous electrical nerve stimulation, reflexology

Phytotherapy and dietary ${ }^{58-61}$ : eg, use of herbal extracts in tea and medication, arnica pad, herbs, dietary consultations according to indication

Homeopathy ${ }^{64}:$ eg, substances that come from minerals, plants, or animals, such as arnica, or crushed whole bees

Abbreviation: $\mathrm{CBT}$, cognitive behavioral therapy. 
Every week, at least two extensive discussions were held with the patients, which focused especially on lifestyle regulative therapy. ${ }^{71,72}$

The medication therapy for both groups was oriented on the requirements of the German S3 Guidelines. ${ }^{73}$ Due to the psychological comorbidities, patients were additionally treated with tricyclic antidepressants.

The therapy progression and the therapy targets were evaluated in weekly, interdisciplinary team meetings and deviations were documented. ${ }^{74}$

\section{Hyperthermia therapy}

In this study, the hyperthermia method used was wholebody hyperthermia with IR radiation (method according to Dr Heckel).$^{75}$ This contains a high fraction of wavelengths near the visible region (ie, short-wave IR, IR-A) and is emitted together with light. The total reflection scattering of the primary radiation produces an even surface irradiation tolerated by the skin. Fractions of this radiation penetrate through the outermost layers of skin and are absorbed in a depth of tissue at which the blood carries the released heat and distributes it throughout the body.

Heat losses are reduced by the individual lying in an insulated cubicle during the irradiation. A window opening in the roof of the cubicle allows air exchange. Pulse rate and temperature were monitored continuously by therapeutic stuff. If required, pulse or electrocardiogram monitoring, oxygen administration, or an intravenous infusion could be implemented during treatment.

The hyperthermia treatment must not be used in the case of existing or threatening thrombosis, Marcumar medication (medication that may influence blood coagulation), or peripheral arterial occlusive disease. Figure 2 gives a summary overview of the indications and contraindications of systemic whole-body hyperthermia.

A comprehensive, therapy-related, patient-related, survey was performed which recorded all the therapy methods used in both groups during the period of hospitalization and presents the intensity of the service provided by integrative multimodal therapy.

\section{Outcome parameters}

The parameters (Mainz Pain Staging System, disease activity, physical symptoms, functional capacity) were conducted by a coordinator, who coordinates clinical activities and shares information with everyone in the workflow. These parameters were controlled by physicians, therapists, and nurses.

For the measurement of chronic pain, the Mainz staging (Gerbershagen) was used. The Mainz Pain Staging System

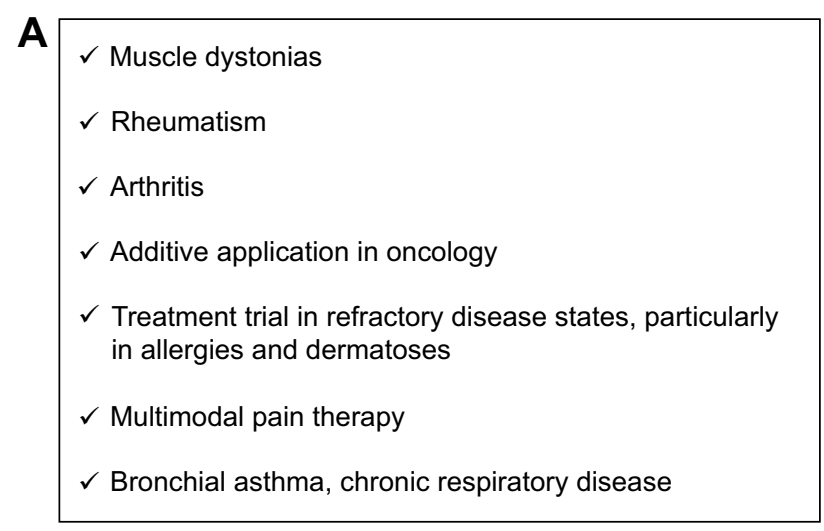

B Existing or impending thrombosis
- Far advanced destructive inflammation of internal organs,
such as progressive pulmonary tuberculosis, acute and
progressive chronic hepatitis and nephritis, and liver
cirrhosis
- Cardiac insufficiency (>2nd degree), severe arrhythmia
- Advanced coronary atherosclerosis
- Pronounced dehydration with disorders of water-
electrolyte

Figure 2 Hyperthermia indications and contraindications.

Notes: (A) Indications for systemic whole-body hyperthermia. (B) Contraindications for systemic whole-body hyperthermia.

is an instrument for the classification of chronic pain in three stages 1, 2, and 3 (ranging from acute $=1$ to chronic pain $=3) .{ }^{76}$ It is based on a questionnaire taking into account dimensions of pain patterns of occurrence, duration, change of intensity, medication usage, and the lifetime utilization of the health care system. ${ }^{77}$

To measure the intensity of pain, the visual analog scale (VAS) was used. The VAS is a psychometric response scale to measure the intensity or frequency of various symptoms. ${ }^{78}$ Respondents mark the location on the $10 \mathrm{~cm}$ line corresponding to the amount of pain they experienced $(0=$ no pain, $10=$ worst pain ever). VAS has been widely used in diverse adult populations, including those with rheumatic diseases. ${ }^{79}$

\section{List of symptoms according to von Zerssen}

The patients' physical symptoms were recorded in the study using this instrument. The procedure is used both in somatic medicine and in clinical psychology and psychiatry. ${ }^{80,81}$ Information can be gathered for all patients with chronified physical and mental diseases or disturbances. The use of the list of symptoms is suitable both for 
an individual and for a group setting. The patients answer questions (Figure 3).

The items included general symptoms (eg, feeling of weakness, fatigue), localizable physical symptoms (eg, pain in the joints and limbs), and mental states (eg, inner restlessness, brooding). The degree of severity of the symptoms surveyed is classified according to a four-level Likert scale (strong-moderate-hardly-not at all).

The individual complaints can be evaluated on a scale with the response categories "not at all" (0 point), "hardly" (1 point), "moderate" ( 2 points), and "strong" (3 points). The addition of the score results in a sum value divided into three groups ("unremarkable", "borderline", and "conspicuous").

The internal consistency (Cronbach's alpha) is $\alpha=0.94$. The split half reliability is very highly pronounced at $r=0.93$. Criteria-related validity is 0.62 .

\section{Functional capacity}

The functional capacity of all subjects was recorded using the Hannover Function Questionnaire (Funktionsfragebogen Hannover) $(\mathrm{FFbH}){ }^{82}$ This tool is a patient self-evaluation instrument for everyday recording of functional limitations resulting from diseases of the locomotor organs. Validity and reliability in repeated measurements are greater than 0.75 . $\mathrm{The} \mathrm{FFbH}$ can be used in a variety of rheumatic diseases and together with other assessment instruments. ${ }^{83}$ The FFbH is sensitive to change, and appears to be of practical usefulness in clinical and epidemiological studies. The defined pool of items strives, on the one hand, to ensure the "everyday relevance" of the movement progressions recorded and the best possible representation of different areas of life and, on the other, to take account of rheumatological aspects. A total of 18 questions are provided for recording functional limitations of the activities of daily life. The grade of the

\begin{tabular}{|ll|}
\hline What symptoms do you have? & \\
- Globus sensation, tightness, or & - Profuse sweating \\
choking in the throat & - Cross or back pain \\
- Shortness of breath & - Heaviness or fatigue in the legs \\
- Feeling of weakness & - Restlessness in the legs \\
- Difficulty in swallowing & - Hypersensitivity to heat \\
- Stitches, pain, or pulling in the & - Hypersensitivity to cold \\
chest & - Insomnia \\
- Pressure or fullness in the & - Dizziness \\
abdomen & - Trembling \\
- Fatigue & - Neck or shoulder pain \\
- Nausea & - Weight loss \\
- Heartburn or acid regurgitation & \\
- Irritability & \\
- Brooding & \\
\hline
\end{tabular}

Figure 3 von Zerssen symptom list. remaining functional capacity is expressed as a percentage of the maximum number of points achieved. A score of $0 \%$ indicates maximum limitation and $100 \%$ stands for an unlimited capability to perform the activities required in daily life. If more than two questions are not answered, the $\mathrm{FFbH}$ should not be evaluated. $\mathrm{FFbH}$ scores of $100 \%$ to approximately $80 \%$ correspond to a "normal" functional capacity; scores $<70 \%$ are an indication of limited functional capacity.

\section{Statistical analysis}

Statistical analyses were performed using SPSS for Windows, Version 20.0 (SPSS Inc, Chicago, IL, USA). For the comparison of two independent, normally distributed samples, the $t$-test was applied. Before that, the homogeneity of the variances was tested by means of the Levene test. When homogeneity of the variances was proven, Student's $t$-test was carried out and when non-homogeneity of variances was tested, the Welch test was used. However, for non-normally distributed samples the Mann-Whitney $U$-test was applied as a nonparametric procedure. The metric variables were presented as means and medians, while the spreads were stated as standard deviations and interquartile ranges.

Normal distribution tests were used to check the distribution form of constant numbers of a sample. A significant deviation from the normal distribution exists at $P<0.05$. In such cases, nonparametric tests must be used for the variables concerned. The normal distribution tests in this study were performed using the Kolmogorov-Smirnov test. Comparison of two independent, normally distributed samples was done using the $t$-test. Comparison of two independent, non-normally distributed samples was done using the Mann-Whitney $U$-test.

The graphics were also produced using SPSS. Boxand-whisker plots were drawn to present the medians and quartiles. The median and 25 th-75th quartiles are entered in the box, while the whiskers correspond to the smallest and largest value as long as these are neither extreme values nor outliers. Outliers are defined as values lying 1.5-3 box lengths outside the box and are shown as circles in the diagrams; extreme values, which measure more than 3 box lengths outside the box, are entered as crosses.

\section{Findings}

A total of 104 patients were studied; the average age of all fibromyalgia patients was 56.05 years (Table 2). A total of 272 hyperthermia treatments were performed in the hyperthermia group (HG). During their stay in hospital, the HG received on average 4.86 hyperthermia sessions (hs) ( $0-2$ hs, 
Table 2 Sociodemographic details of CG versus HG

\begin{tabular}{lll}
\hline & CG & HG \\
\hline Female/male & $47 / I$ & $55 / 1$ \\
Age (mean) & 57 & 55.1 \\
Age (median) & 56.0 & 54.5 \\
Age (range in years) 16-38 & 2 & 3 \\
Age (range in years) $39-49$ & 6 & 11 \\
Age (range in years) $50-55$ & 11 & 18 \\
Age (range in years) 56-65 & 17 & 16 \\
Age (range in years) 65 and older & 12 & 8 \\
Total (N) & 48 & 56 \\
\hline
\end{tabular}

Abbreviations: CG, control group; HG, hyperthermia group.

$\mathrm{N}=0 ; 3-4$ hs, $\mathrm{N}=10 ; 5-6$ hs, $\mathrm{N}=46$ ) in the mildly warm temperature range between $37.5^{\circ} \mathrm{C}$ and $38.5^{\circ} \mathrm{C}$.

All patients showed a polysymptomatic progression with lasting, persistent pain in muscles and joints, and with rare intervals with reduced symptoms. The overwhelming majority of the patients were subject to private and/or professional stressors with health-related anxieties. The disease activity was elevated significantly and all subjects suffered from considerable morning stiffness.

The great majority of the patients were in Stage 3 of the Mainz Pain Staging System according to Gerbershagen.

As part of the study, an analysis of secondary diagnoses was performed involving the comparison of several hundred secondary diagnoses. The basis of the analysis was allocation of the diagnoses in accordance with the International Statistical Classification of Diseases and Related Health Problems and the Major Diagnostic Category. Comparison of the secondary diagnoses revealed only a significant difference of Diagnostic Category "Circulatory system” in control group (CG) vs HG (Mann-Whitney $U$-test, asymptotic significance [two-tailed], $P=0.049$ ). This had no influence on results because this was no exclusion criterion for $\mathrm{HG}$. There was no significant difference between the age of the two groups ( $t$-test, $P=0.350$ ). The members of both groups were predominantly female (48 women in $\mathrm{CG}$; 56 women in $\mathrm{HG})$.

Hospitalization for the HG was 16.2 days (minimum 12 days and maximum 17 days, standard deviation 1.1) and in the CG 15.7 days (minimum 10 days and maximum 19 days, standard deviation 2.2). Comparison of CG and $\mathrm{HG}$ showed no significant difference (Mann-Whitney $U$-test, asymptotic significance [two-tailed], $P=0.211$ ).

The mean level of pain (admission) was 6.8 (CG) on the VAS and 8.2 (HG). The mean level of pain (discharge) was 4.8 (CG) on the VAS and $4.0(\mathrm{HG})$.

\section{Functional capacity on admission and discharge}

The functional capacity was measured for all the patients from both groups. All the patients in the two groups answered all the questions. On admission, no significant difference could be established between the two groups ( $t$-test; $P=0.936$ ). The standard deviation in the $C G$ was 20.1 (median 58.0, maximum 94.0) and in the HG it was 14.6 (median 58.0, maximum 91.0). On discharge, there was a significant difference (Mann-Whitney $U$-test; asymptotic significance, $P=0.039$ ) (Figure 4). The standard deviation in the HG was 19.1 (median 75.0, maximum 100.0) and in the CG it was 18.8 (median 62.0, maximum 97.0).

\section{Symptoms according to von Zerssen on admission and discharge}

All the members of both groups answered all the questions in the questionnaire. The survey of the list of symptoms according to von Zerssen revealed no significant differences between the two groups on their admission to hospital ( $t$-test; $P=0.988)$. The standard deviation for the HG was 9.4 (median 42.0) and for the CG 12.2 (median 41.0) on admission (Table 3). A significant difference was evident on discharge ( $t$-test; $P=0.024)$. The standard deviation for the CG was 14.6 (median 37.5) and for the HG it was 12.0 (median 29.0) (Figure 5 and Table 4).

\section{Analysis of the therapy density of the therapy areas for both groups \\ Physical therapy (hydrotherapy)}

Comparison of the amounts of physical therapy (hydrotherapy) received by the two groups showed no significant difference (Mann-Whitney $U$-test, asymptotic significance

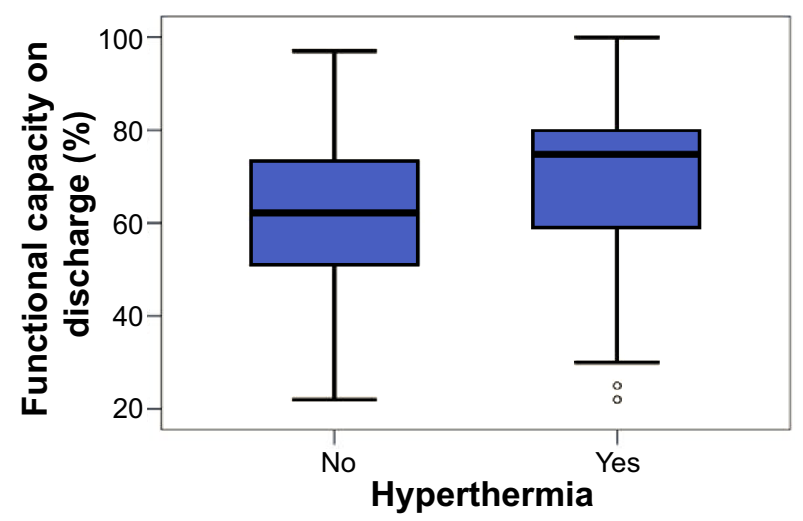

Figure 4 Functional capacity on discharge in patients with versus without hyperthermia. 
Table 3 von Zerssen on admission with versus without hyperthermia

\begin{tabular}{lll}
\hline & \multicolumn{2}{l}{ von Zerssen on admission } \\
\cline { 2 - 3 } & \multicolumn{1}{l}{ Hyperthermia } \\
\cline { 2 - 3 } & CG & HG \\
\hline Mean & 41.8 & 41.8 \\
Standard deviation & 12.2 & 9.4 \\
Standard error of mean & 1.8 & 1.3 \\
Percentile 25 & 34.0 & 35.5 \\
Median & 41.0 & 42.0 \\
Percentile 75 & 48.5 & 48.0 \\
Minimum & 13 & 21 \\
Maximum & 67 & 60 \\
Count & 48 & 56 \\
Total $(\mathrm{N})$ & 48 & 56 \\
\hline
\end{tabular}

Abbreviations: CG, control group; HG, hyperthermia group.

[two-tailed], $P=0.979)$. The standard deviation for the HG was 308.4 (median 97.5) and for the CG it was 105.9 (median $120.0)$.

\section{Physical therapy (thermotherapy)}

The difference measured in therapy minutes between the amounts of physical therapy (thermotherapy) was significant (Mann-Whitney $U$-test, asymptotic significance [two-tailed], $P=0.000$ ). The mean for the $C G$ was 330.8 minutes and for the HG 693.7 minutes. The standard deviation for the HG was 321.5 (median 785.0) and for the CG it was 138.8 (median 340.0) (Table 5).

\section{Physiotherapy}

Comparison of the amounts of physiotherapeutic intervention showed a significant difference between the groups (Mann-Whitney $U$-test, asymptotic significance [two-tailed], $P=0.000$ ). The mean for physiotherapeutic interventions in the CG was 492.4 minutes compared with 284.2 minutes in the HG. The standard deviation for the HG was 222.8

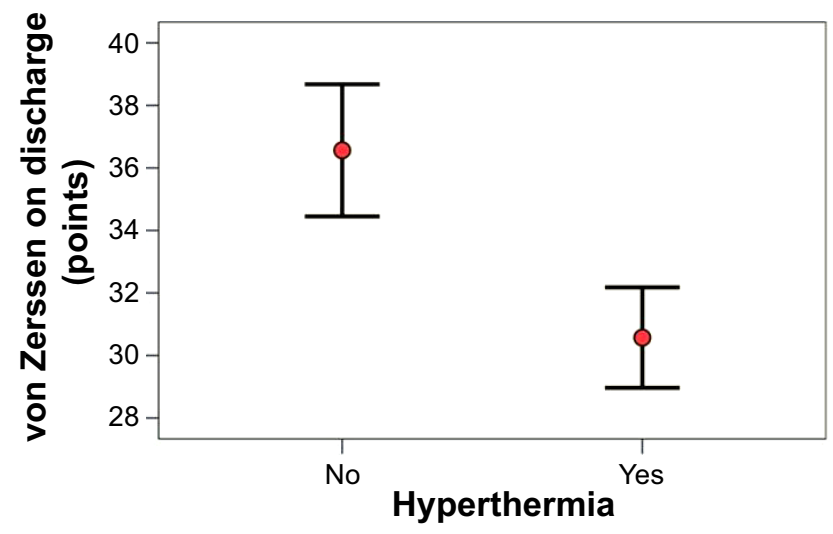

Figure 5 von Zerssen on discharge in patients with versus without hyperthermia.
Table 4 von Zerssen on discharge with versus without hyperthermia

\begin{tabular}{lll}
\hline & \multicolumn{2}{l}{ von Zerssen on discharge } \\
\cline { 2 - 3 } & \multicolumn{2}{l}{ Hyperthermia } \\
\cline { 2 - 3 } & CG & HG \\
\hline Mean & 36.6 & 30.6 \\
Standard deviation & 14.6 & 12.0 \\
Standard error of mean & 2.1 & 1.6 \\
Percentile 25 & 28.0 & 21.5 \\
Median & 37.5 & 29.0 \\
Percentile 75 & 45.5 & 39.5 \\
Minimum & 5 & 9 \\
Maximum & 65 & 55 \\
Count & 48 & 56 \\
Total $(\mathrm{N})$ & 48 & 56 \\
\hline
\end{tabular}

Abbreviations: CG, control group; HG, hyperthermia group.

(median 222.5) and for the CG it was 239.6 (median 437.5) (Table 5).

\section{Phytotherapy}

The mean time taken up by phytotherapeutic interventions was 154 minutes for the $\mathrm{CG}$ and 176.4 minutes for the HG. There was no significant difference (Mann-Whitney $U$-test, asymptotic significance, $P=0.506$ ).

\section{Psychotherapy/mind body medicine}

Comparison of the two groups revealed no significant difference (Welch test, $P=0.199$ ). The standard deviation for the HG was 134.6 (median 507.5) and for the CG it was 207.0 (median 605.0).

\section{Movement therapy}

The mean amount of movement therapy for the CG was 476.4 minutes (standard deviation 229.2, median 320.0) and for the HG 307.0 minutes (standard deviation 202.3, median 167.5) (Table 5). Comparison of the two groups revealed a significant difference in the therapeutic effort ( $t$-test, $P<0.001)$.

\section{Detoxifying process}

There was no significant difference for the detoxifying process in patients receiving and not receiving hyperthermia (Mann-Whitney $U$-test, asymptotic significance, $P=0.452$ ). The standard deviation for the HG was 44.8 (median 100.0) and for the CG it was 32.5 (median 90.0).

\section{Neural therapy/infiltration/acupuncture}

Regarding the amount of therapy in the procedures of neural therapy/infiltration/acupuncture, no significant difference was observed between patients receiving and not receiving 
Table 5 Physical therapy/thermotherapy, physiotherapy, movement therapy, and homeopathy in patients with versus without hyperthermia (intervention in minutes)

\begin{tabular}{|c|c|c|c|c|c|c|c|c|}
\hline & \multirow{2}{*}{\multicolumn{2}{|c|}{$\begin{array}{l}\text { Physical therapyl } \\
\text { thermotherapy } \\
\text { Hyperthermia }\end{array}$}} & \multirow{2}{*}{\multicolumn{2}{|c|}{$\begin{array}{l}\text { Physiotherapy } \\
\text { Hyperthermia } \\
\end{array}$}} & \multirow{2}{*}{\multicolumn{2}{|c|}{$\begin{array}{l}\text { Movement therapy } \\
\text { Hyperthermia } \\
\end{array}$}} & \multirow{2}{*}{\multicolumn{2}{|c|}{$\begin{array}{l}\text { Homeopathy } \\
\text { Hyperthermia } \\
\end{array}$}} \\
\hline & & & & & & & & \\
\hline & CG & HG & CG & HG & CG & HG & CG & HG \\
\hline Mean & 330.8 & 693.7 & 492.4 & 284.2 & 476.4 & 307.0 & 46.9 & 31.6 \\
\hline Standard deviation & 138.8 & 321.5 & 239.6 & 222.8 & 229.2 & 202.3 & 62.5 & 55.6 \\
\hline Percentile 25 & 267.5 & 397.5 & 335.0 & 115.0 & 33.1 & 27.0 & 0.0 & 0.0 \\
\hline Median & 340.0 & 785.0 & 437.5 & 222.5 & 320.0 & 167.5 & 0.0 & 0.0 \\
\hline Percentile 75 & 412.5 & 917.5 & 640.0 & 352.5 & 470.0 & 315.0 & 120.0 & 30.0 \\
\hline Minimum & 0 & 30 & 120 & 0 & 40 & 0 & 0 & 0 \\
\hline Maximum & 695 & $\mathrm{I}, 240$ & 1,080 & 840 & 950 & 850 & 180 & 150 \\
\hline Count & 48 & 56 & 48 & 56 & 48 & 56 & 48 & 56 \\
\hline Total (N) & 48 & 56 & 48 & 56 & 48 & 56 & 48 & 56 \\
\hline
\end{tabular}

Abbreviations: CG, control group; HG, hyperthermia group.

hyperthermia (Mann-Whitney $U$-test, asymptotic significance, $P=0.157$ ). The standard deviation for the $\mathrm{HG}$ was 103.4 (median 60.0) and for the CG it was 87.7 (median 75.0).

\section{Homeopathy}

No significant difference was observed between the homeopathy inputs for the two groups (Mann-Whitney $U$-test, asymptotic significance [two-tailed], $P=0.085$ ). The standard deviation for the HG was 55.6 and for the CG it was 62.5 (Table 5).

\section{Diet advice}

The outlay for diet advice was not significantly different between the two groups (Mann-Whitney $U$-test, asymptotic significance [two-tailed], $P=0.866$ ). The standard deviation for the HG was 21.3 (median 0) and for the CG it was 25.8 (median 0).

\section{Discussion and conclusion}

The participants were predominantly female, as also reported by other studies. ${ }^{84,85}$ The longer hospitalization time of these integratively treated patients also agrees with the findings of previous large-scale scientific studies. ${ }^{56}$

The mean age of the patients in this study corresponds with the analysis of ages ascertained at the German national level. Out of 6.452 inpatients in Germany whose main diagnosis was FMS, $>55 \%$ of patients in 2008 were between 40 years and 59 years of age. Software: G-DRG-Browser G-DRG-Version 2011, Daten 2010 gem; §21 KHEntgG.

For 2011, data were available for 1,929 cases receiving inpatient treatment, of whom the majority also fell within this age range. ${ }^{86}$

This study shows that interdisciplinary therapeutic approaches are worthwhile in the treatment of FMS.
Despite the severity of the disease with a pain-supporting mental-accompanying disease, a significant improvement in the symptoms was evident on discharge from hospital $(P=0.024$; Tables 3 and 4). The complex somatic and mental symptoms that were recorded with the von Zerssen score could also be alleviated by means of the complementary use of hyperthermia. The use of hyperthermia improved the outcome still further. The superior outcome for the HG was manifested in a significant improvement in the patient's functional capacity. A greater therapeutic density of both physiotherapeutic interventions and methods of movement therapy in the CG proved unable to equal the added benefit of hyperthermia. Whole-body hyperthermia is a part of a multidisciplinary approach. ${ }^{48,53}$ Previous studies with hyperthermia were performed in a rehabilitative setting. ${ }^{52,53,87,88}$ Hyperthermia has been carried out for several weeks. A sustained pain reduction was observed in a 6-month follow-up after intervention ended in patients with FMS. ${ }^{52}$ There were no specifications for other therapy methods, and their density and the form of progression were not described accurately.

Acute care is a care setting where an individual is treated for a brief but severe episode of illness. Acute programs in Germany have increased numbers of sessions and a larger care team. Acute care settings have full-time physicians and hospital staff who are available 24 hours a day. The aim of acute inpatient treatment is to improve the patients' condition sufficiently that they are once again capable of rehabilitation. ${ }^{89}$ Continual acute diagnosis (in the case of an emergency situation or diagnosis aggravation) and therapy, and continual medical and nursing care are guaranteed during the entire period of hospitalization. Proven applications are summarized in Figure 6.

In future studies for the evaluation of the therapy of FMS, economic parameters must also be analyzed in order to perform diagnosis-related group (system to classify hospital 
- Active patient participation

- Refer to specialists (rheumatologist, pain specialist, physiatrist, or psychiatrist)

- Specially trained nursing staff with experience of naturopathy, staff including physiotherapists, ergonomic therapists, psychologists

- Multicomponent therapy with: balneotherapy, strength training, acupuncture, exercise training, cognitive behavioral therapy

- Hyperthermia should be considered as a part of a multidisciplinary approach

Figure 6 Applications for clinical practice (fibromyalgia syndrome).

cases into groups) cost calculations (in addition to clinical effects), especially regarding the costs associated with claims for outpatient and inpatient therapy for FMS. In doing so, the question should be addressed as to whether the use of innovative, integrative therapeutic methods can generate the potential for long-term savings.

In addition, observational studies are needed of mildly warm whole-body hyperthermia treatment of further diseases and disturbances of the musculoskeletal system and connective tissues in acute inpatient therapy of pain and rheumatic diseases with the inclusion of complementary medical procedures. The development of further improved therapies for treating FMS, as well as analysis of delivery methods of each modality and how they potentially influence one another and also the recidivism in different hospital settings, is necessary.

\section{Acknowledgment}

The authors would like to thank the anonymous reviewers for reviewing the paper.

\section{Disclosure}

The authors have no conflict of interest.

\section{References}

1. Wolfe F, Clauw DJ, Fitzcharles MA, et al. The American College of Rheumatology preliminary diagnostic criteria for fibromyalgia and measurement of symptom severity. Arthritis Care Res. 2010;62(5): 600-610.

2. Mease P, Arnold LM, Choy EH, et al; OMERACT Fibromyalgia Working Group. Fibromyalgia syndrome module at OMERACT 9: domain construct. $J$ Rheumatol. 2009;36(10):2318-2329.

3. Aguglia A, Salvi V, Maina G, Rossetto I, Aguglia E. Fibromyalgia syndrome and depressive symptoms: comorbidity and clinical correlates. $J$ Affect Disord. 2011;128(3):262-266.

4. Marangell LB, Clauw DJ, Choy E, et al. Comparative pain and mood effects in patients with comorbid fibromyalgia and major depressive disorder: secondary analyses of four pooledrandomized controlled trials of duloxetine. Pain. 2011;152(1):31-37.
5. Epstein SA, Kay G, Clauw D, et al. Psychiatric disorders in patients with fibromyalgia: a multicenter investigation. Psychosomatics. 1999; 40(1):57-63.

6. Mease PJ, Arnold LM, Crofford LJ, et al. Identifying the clinical domains of fibromyalgia: contributions from clinician and patient delphi exercises. Arthritis Rheum. 2008;59(7):952-960.

7. Wolfe F, Smythe HA, Yunus MB, et al. The American College of Rheumatology 1990 criteria for classification of fibromyalgia. Arthritis Rheum. 1990;33:160-172.

8. Abeles AM, Pillinger MH, Solitar BM, Abeles M. The pathophysiology of fibromyalgia. Ann Intern Med. 2007;146:726-734.

9. Dedhia JD, Bone ME. Continuing education in anaesthesia, critical care and pain (Oxford University Press). Pain Fibromyalgia. 2009;9(5): $162-166$.

10. Mork PJ, Vasseljen O, Nilsen TI. Association between physical exercise, body mass index, and risk of fibromyalgia: longitudinal data from the Norwegian Nord-Trøndelag Health Study. Arthritis Care Res. 2010;62:611-617.

11. Kivimäki M, Leino-Arjas P, Virtanen M, et al. Work stress and incidence of newly diagnosed fibromyalgia: prospective cohort study. J Psychosom Res. 2004;57(5):417-422.

12. Van Liew C, Brown KC, Cronan TA, Bigatti SM, Kothari DJ. Predictors of pain and functioning over time in fibromyalgia syndrome: an autoregressive path analysis. Arthritis Care Res. 2013;65(2): 251-256.

13. Branco JC, Bannwarth B, Failde I, et al. Prevalence of fibromyalgia: a survey in five European countries. Semin Arthritis Rheum. 2010;39(6): 448-453.

14. Perrot $S$, Vicaut E, Servant $D$, Ravaud P. Prevalence of fibromyalgia in France: a multi-step study research combining national screening and clinical confirmation: the DEFI study (determination of epidemiology of fibromyalgia). BMC Musculoskelet Disord. 2011; $12: 224$.

15. Schaefer C, Chandran A, Hufstader M, et al. The comparative burden of mild, moderate and severe fibromyalgia: results from a crosssectional survey in the United States. Health Qual Life Outcomes. 2011;9:71.

16. Annemans L, Le Lay K, Taieb C. Societal and patient burden of fibromyalgia syndrome. Pharmacoeconomics. 2009;27(7):547-559.

17. Lachaine J, Beauchemin C, Landry PA. Clinical and economic characteristics of patients with fibromyalgia syndrome. Clin J Pain. 2010; 26(4):284-290.

18. Gore M, Tai KS, Chandran A, Zlateva G, Leslie D. Clinical characteristics, pharmacotherapy, and healthcare resource use among patients with fibromyalgia newly prescribed pregabalin or tricyclic antidepressants. J Med Econ. 2012;15(1):32-44.

19. Anwar F, Fahim S. Fibromyalgia: a complex pain problem. Khyber Med Univ J. 2013;5(1):40-44.

20. Carbonell-Baeza A, Aparicio VA, Ortega FB, et al. Does a 3-month multidisciplinary intervention improve pain, body composition and physical fitness in women with fibromyalgia? Br J Sports Med. 2011;45(15): 1189-1195.

21. Häuser W, Tieme K, Turk DC. Guidelines on the management of fibromyalgia syndrome a systematic review. Eur J Pain. 2010;14(1): $5-10$.

22. Romeyke T, Stummer H. Clinical pathways as instruments for risk and cost management in hospitals - a discussion paper. Global J Health Sci. 2012;4(2):50-59.

23. Bennett RM, Jones J, Turk DC, Russell IJ, Matallana L. An internet survey of 2,596 people with fibromyalgia. BMC Musculoskelet Disord. 2007;8:27.

24. McVeigh JG, McGaughey H, Hall M, Kane P. The effectiveness of hydrotherapy in the management of fibromyalgia syndrome: a systematic review. Rheumatol Int. 2008;29:119-130.

25. Ozkurt S, Dönmez A, Zeki Karagülle M, Uzunoğlu E, Turan M, Erdoğan N. Balneotherapy in fibromyalgia: a single blind randomized controlled clinical study. Rheumatol Int. 2012;32(7):1949-1954. 
26. Yurtkuran M, Celiktas M. A randomized, controlled trial of balneotherapy in the treatment of patients with primary fibromyalgia syndrome. Phys Rehab Kur Med. 1996;6:109-112.

27. Mannerkorpi K, Henriksson C. Pool exercise combined with an education programme for patients with fibromyalgia syndrome. A prospective, randomized study. J Rheumatol. 2000;27:473-481.

28. Jentoft ES, Kvalvik G, Mengshoel AM. Effects of pool-based and landbased aerobic exercise on women with fibromyalgia/chronic widespread muscle pain. Arthritis Rheum. 2001;45:42-47.

29. Chandola HC, Chakraborty A. Fibromyalgia and Myofascial Pain Syndrome-A Dilemma. Indian J Anaesth. 2009;53(5):575-581.

30. National Institutes of Health. Consensus conference. Acupuncture. [Review]. JAMA. 1998;280(17):1518-1524.

31. Singh BB, Wu WS, Hwang SH, et al. Effectiveness of acupuncture in the treatment of fibromyalgia. Altern Ther Health Med. 2006;12(2):34-41.

32. Sprott H, Franke S, Kluge H, Hein G. Pain treatment of fibromyalgia by acupuncture (abstract). Arthritis Rheum. 1996;39:S91.

33. Targino RA, Imamura M, Kaziyama HH, et al. A randomized controlled trial of acupunture added to usual treatment for fibromyalgia. J Rehabil Med. 2008;40:582-588.

34. Astin JA, Berman BM, Bausell B, Lee WL, Hochberg M, Forys KL. The efficacy of mindfulness meditation plus Qigong movement therapy in the treatment of fibromyalgia: a randomized controlled trial. $J$ Rheumatol. 2003;30(10):2257-2262.

35. Jensen MP, Turner JA, Romano JM, Karoly P. Coping with chronic pain: a critical review of the literature. Pain. 1991;47:249-283.

36. Boehm A, Eisenberg E, Lampel S. The contribution of social capital and coping strategies to functioning and quality of life of patients with fibromyalgia. Clin J Pain. 2011;27(3):233-239.

37. Ortega E, García JJ, Bote ME, et al. Exercise in fibromyalgia and related inflammatory disorders: know effects and unknown chances. Exerc Immunol Rev. 2009;15:42-65.

38. Thieme K, Spies C, Sinha P, Turk DC, Flor H. Predictors of pain behaviors in fibromyalgia syndrome. Arthritis Rheum. 2005;53: 343-350.

39. Busch AJ, Barber KA, Overend TJ, Peloso PM, Schachter CL. Exercise for treating fibromyalgia syndrome. Cochrane Database Syst Rev. 2007; 4:CD003786

40. Gunnarsdottir TJ, Peden-McAlpine C. Effects of reflexology on fibromyalgia symptoms: a multiple case study. Complement Ther Clin Pract. 2010;16(3):167-172.

41. Liapi E, Geschwind JF. Hyperthermia - description of a method and a review of clinical applications. Rep Pract Oncol Radiother. 2007;12(5):267-275.

42. Takahashi K, Kurosaki H, Hashimoto S, Takenouchi K, Kamada T, Nakamura H. The effects of radiofrequency hyperthermia on pain and function in patients with knee osteoarthritis: a preliminary report. J Orthop Sci. 2011;16(4):376-381.

43. Foerster J, Fleischanderl S, Wittstock S, et al. Infrared-mediated hyperthermia is effective in the treatment of scleroderma-associated raynaud's phenomenon. J Invest Dermatol. 2005;125:1313-1316.

44. Ismail-Zade RS, Zhavrid EA, Potapnev MP. Whole body hyperthermia in adjuvant therapy of children with renal cell carcinoma. Pediatr Blood Cancer. 2005;44(7):679-681.

45. Aktas M, Jong de D, Nuyttens JJ. Concomitant radiotherapy and hyperthermia for primary carcinoma of the vagina: a cohort study. Eur J Obstet Gynecol Reprod Biol. 2007;133(1):100-104.

46. Karu TI. Mitochondrial signaling in mammalian cells activated by red and near-IR radiation. Photochem Photobiol. 2008;84(5):1091-1099.

47. Applegate LA, Scaletta C, Panizzon R, Frenk E, Hohlfeld P, Schwarzkopf S. Induction of the putative protective protein ferritin by infrared radiation: implications in skin repair. Int J Mol Med. 2000;5(3): 247-251.

48. Wust P, Hildebrandt B, Sreenivasa G, et al. Hyperthermia in combined treatment of cancer. Lancet Oncol. 2002;3:487-497.
49. Mercer JB, Nielsen SP, Hoffmann G. Improvement of wound healing by water-filtered infrared-A (wIRA) in patients with chronic venous stasis ulcers of the lower legs including evaluation using infrared thermography. GMS Ger Med Sci. 2008;6:Doc11.

50. Hartel M, Hoffmann G, Wente MN, Martignoni ME, Büchler MW, Friess H. Randomized clinical trial of the influence of local waterfiltered infrared A irradiation on wound healing after abdominal surgery. Br J Surg. 2006;93(8):952-960

51. Ettrich U, Konrad B, Prate K, Seifert J, et al. Milde Ganzkörperhyperthermie in Kombination mit stationärer multimodal orientierter Schmerztherapie [Mild whole-body hyperthermia in combination with inpatient multimodal pain therapy]. Orthopäde. 2014;43:165-174. German.

52. Brockow T. Mild water-filtered near-infrared whole-body hyperthermia as an adjunct to a standard multimodal rehabilitation in the treatment of fibromyalgia: results from a randomized controlled trial. Eur J Integr Med. 2008;1(1):15.

53. Walz J, Hinzmann J, Haase I, Witte T. Ganzkörperhyperthermie in der Schmerztherapie. Schmerz. 2013;27(1):38-45.

54. Frettlöh J, Maier C, Gockel H, Hüppe M. Validation of the German Mainz pain staging system in different pain syndromes. Schmerz. 2003; 17(4):240-251.

55. Schmitt N, Gerbershagen HU. The mainz pain staging system (MPSS) for chronic pain. Pain. 1990;41:484-490.

56. Romeyke T, Stummer H. Interdisciplinary complex therapies in inpatient hospital treatment in Germany: evidence from Germany. J Manage Market Healthcare. 2011;4(4):208-216.

57. Romeyke T, Stummer H. Holistic care. Heilberufe Sci. 2013;4(1): $15-20$.

58. Logan AC. Dietary modifications and fibromyalgia. J Evidence-Based Complementary Altern Med. 2003;8(3):234-245.

59. Donaldson MS, Speight N, Loomis S. Fibromyalgia syndrome improved using a mostly raw vegetarian diet: an observational study. $B M C$ Complement Altern Med. 2001;1:7.

60. Kartinen K, Lammi K, Hypen M, Hänninen O, Rauma AL. Vegan diet alleviates fibromyalgia symptoms. Scand J Rheumatol. 2000;29: 308-313.

61. Hänninen O, Rauma AL. Fibromyalgia and diet. In: Coleman LA, editor. Nutrition and Rheumatic Disease. Nutrition and Health. Totowa, NJ: Humana Press; 2008:183-193.

62. Joaquim J, Soares F, Grossi G. A randomized, controlled comparison of educational and behavioural interventions for women with fibromyalgia. Scand J Occup Ther. 2002;9:35-45.

63. Glombiewski JA, Sawyer AT, Gutermann J, Koenig K, Rief W, Hofmann SG. Psychological treatments for fibromyalgia: a metaanalysis. Pain. 2010;151:280-295.

64. Ernst E. Complementary medicine. Curr Opin Rheumatol. 2003;15: 151-155.

65. Ammer K, Melnizky P. Medicinal baths for treatment of generalized fibromyalgia. Forsch Komplementarmed. 1999;6(2):80-85.

66. Langhorst J, Musial F, Klose P, Häuser W. Efficacy of hydrotherapy in fibromyalgia syndrome - a meta-analysis of randomized controlled clinical trials. Rheumatol (Oxford). 2009;48:1155-1159.

67. Field T, Delage J, Hernandez-Reif M. Movement and massage therapy reduce fibromyalgia pain. J Bodyw Mov Ther. 2003;7(1):49-52.

68. Cao H, Hu H, Colagiuri B, Liu J. Medicinal cupping therapy in 30 patients with fibromyalgia: a case series observation. Forsch Komplementmed. 2011;18(3):122-126.

69. Cao H, Han M, Li X, et al. Clinical research evidence of cupping therapy in China: a systematic literature review. BMC Complement Altern Med. 2010;10:70.

70. Kesiktas N, Karagülle Z, Erdogan N, Yazıcıoglu K, Yılmaz H, Paker N. The efficacy of balneotherapy and physical modalities on the pulmonary system of patients with fibromyalgia. J Back Musculoskelet Rehabil. 2011;24(1):57-65. 
71. Kabat-Zinn J, Lipworth L, Burney R, Sellers W. Four year follow-up of a meditation-based program for the self-regulation of chronic pain: treatment outcomes and compliance. Clin J Pain. 1986;2:159-173.

72. Luskin FM, Newell KA, Griffith M, et al. A review of mind/body therapies in the treatment of musculoskeletal disorders with implications for the elderly. Altern Ther Health Med. 2000;6(2):46-56.

73. Häuser W, Eich W, Herrmann M, Nutzinger DO, Schiltenwolf M, Henningsen P. The Fibromyalgia syndrome: classification, diagnosis, and treatment. Dtsch Ärztebl Int. 2009;106(23):383-391.

74. Romeyke T, Stummer H. A study of costs and length of stay of inpatient naturopathy - evidence from Germany. Complement Ther Clin Pract. 2011;17(2):90-95.

75. Heckel M. Ganzkörperhyperthermie und Fiebertherapie-Grundlagen und Praxis. Stuttgart: Hippokrates; 1990.

76. Pfingsten M, Schöps P, Wille T, Terp L, Hildebrandt J. Classification of chronic pain. Quantification and grading with the Mainz pain staging system. Schmerz. 2000;14(1):10-17.

77. Hüppe M, Matthiessen V, Lindig M, et al. Comparison of severity of chronic pain in patients differing in pain diagnosis: an analysis by means of the Mainz pain staging System. Schmerz. 2001;15:179-185.

78. Streiner DL, Norman GR. Health Measurement Scales: A Practical Guide to Their Development and Use. New York: Oxford University Press; 1989.

79. Downie WW, Leatham PA, Rhind VM, Wright V, Branco JA, Anderson JA. Studies with pain rating scales. Ann Rheum Dis. 1978;37:378-381.

80. von Zerssen D, Petermann F. Bf-SR-Die Befindlichkeits-Skala-Revidierte Fassung. Hogrefe: Göttingen; 2011.

81. Baumann U. A controlled test for the evaluation of the von Zerssen symptom list European. Eur Arch Psychiat Clin Neuros. 1972;216(2):153-161.
82. Lautenschläger J, Mau W, Kohlmann T, et al. Comparative evaluation of a German version of the Health Assessment Questionnaire (HAQ) and the Hannover Functional Status Questionnaire (HFSQ). Z Rheumatol. 1997;56(3):144-155.

83. Raspe HH, Hagedorn T, Kohlman T. Der Funktionsfragebogen Hannover $(\mathrm{FFbH})$ : Ein Instrument zur Funktionsdiagnostik bei polyartikulären Gelenkerkrankungen. In: Siegrist J, editor. Wohnortnahe Betreuung Rheumakranker. Stuttgart: Schattauer; 1999:164-182.

84. Russell IJ. Fibromyalgia syndrome. Diagnosis, pathogenesis, and management. Phys Med Rehabil Clin N Am. 1997;8(1):213-226.

85. Häuser W, Hayo S, Biewer W, et al. Diagnosis of fibromyalgia syndrome - a comparison of Association of the Medical Scientific Societies in Germany, survey, and American College of Rheumatology criteria. Clin J Pain. 2010;26:505-511.

86. InEK, Institut für das Entgeltsystem im Krankenhaus, Auszug: Plausibilisierte Daten bei Versorgung durch Hauptabteilungen des Jahres 2010 und 2012 aus den an der Kalkulation zur Weiterentwicklung des G-DRG-Systems teilnehmenden Krankenhäusern; 2010, 2012.

87. Schleenbecker HG, Schmidt KL. Zur Wirkung einer iterativen milden Ganzkörperhyperthermie auf den Fibromyalgieschmerz [To effect an iterative mild whole-body hyperthermia on the fibromyalgia pain]. Phys Rehab Kur Med. 1998;8:113-117. German.

88. Piso U, Küther G, Gutenbrunner C. Analgesic effects of sauna in fibromyalgia. Phys Rehab Kur Med. 2001;2001(11):94-99.

89. Bochdansky T, Prager C, Ammer K. Allgemeine Rehabilitation. Grundlagen und Prinzipien [General rehabilitation. Foundations and principles]. Österr Z Phys Med Rehabil. 2002;12(2):47-53.
Clinical Interventions in Aging

\section{Publish your work in this journal}

Clinical Interventions in Aging is an international, peer-reviewed journal focusing on evidence-based reports on the value or lack thereof of treatments intended to prevent or delay the onset of maladaptive correlates of aging in human beings. This journal is indexed on PubMed Central, MedLine,

\section{Dovepress}

CAS, Scopus and the Elsevier Bibliographic databases. The manuscript management system is completely online and includes a very quick and fair peer-review system, which is all easy to use. Visit http://www.dovepress. com/testimonials.php to read real quotes from published authors. 